\title{
Artigos
}

C

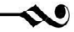

\section{RECEBER, ENVIAR E COMPARTILHAR COMIDA: ASPECTOS DA MIGRAÇÃO VENEZUELANA EM BOA VISTA, BRASIL}

\author{
Receiving, sending and sharing food: \\ aspects of the Venezuelan migration in Boa Vista, Brasil
}

lana dos Santos Vasconcelos*

\begin{abstract}
Resumo. O recente deslocamento de venezuelanos/as para Boa Vista-RR vem sendo observado segundo diferentes perspectivas. Um aspecto ainda pouco explorado é o da alimentação. A maioria desses migrantes procura desempenhar alguma atividade produtiva que gere renda para comprar comida e enviar aos familiares na Venezuela. Sujeitam-se a condições precárias de trabalho e vida. As relações sociais envolvidas na circulação dos alimentos nos convidam a refletir sobre a mobilidade humana. Dar comida, receber e comer junto configuram relações assimétricas e simétricas, com brasileiros/as ou entre venezuelanos/as. O artigo enfoca a agência dos/as venezuelanos/as nessas situações. Podem ser provedores de lares distantes, comensais que se vêm como iguais, e pets ou presas do capitalismo brasileiro.
\end{abstract}

Palavras-chave: comida; agência; venezuelanos/as; brasileiros/as; Boa Vista-RR.

\begin{abstract}
The recent displacement of Venezuelans to Boa Vista-RR has been observed from different perspectives. One aspect still unexplored is food. Most of these migrants seek to carry out some productive activity that generates income to buy food and send it to relatives in Venezuela. They are subjected to precarious working and life conditions. The social relations involved in the circulation of food invite us to reflect on human mobility. Giving food, receiving and eating together configure asymmetrical and symmetrical relationships, with Brazilians or between Venezuelans. The article focuses on the agency of Venezuelans in these situations. They may be providers of distant homes, commensals who come as equals, and pets or prey of Brazilian capitalism.
\end{abstract}

Keywords: food; agency; Venezuelans; Brazilians; Boa Vista-RR.

Programa de Pós-Graduação em Antropologia Social da Universidade Federal de São Carlos (UFSCar). Bolsista FAPESP proc. n.2016/14055-0. São Carlos - SP, Brasil. 


\section{Introdução}

A inserção de migrantes no mercado de trabalho é um tema recorrente nos estudos migratórios. Pesquisas descortinam diferentes formas de exploração e precarização das condições laborais, geralmente associadas ao status de indocumentados/as e às discriminações étnico-raciais, de gênero, religiosas, entre outras (Beheran, Freitas, 2011; Cavalcanti, 2014; Feldman-Bianco, 2015). Não é diferente com os/as venezuelanos/as em Boa Vista, RR. Estudos recentes apontam para as incertezas jurídicas e as vulnerabilidades da condição migrante (Silva, Bógus, Silva, 2017; Simões, 2017). Dentre o complexo das relações laborais nesse contexto migratório, enfatizo aquelas ligadas à alimentação.

Receber, dar e compartilhar comida são facetas pouco exploradas no âmbito das discussões sobre migração e trabalho. A acentuação da migração de venezuelanos/as para a cidade de Boa Vista, Roraima, vem revelando peculiaridades do deslocamento humano. A busca pela comida coloca o indivíduo em movimento, expondo fragilidades, mas também revelando capacidades. Por um lado, gera relações de dependência econômica com os/ as brasileiros/as, por outro, ocasiona o empoderamento de provedores/as de famílias transnacionais e contribui para a comunhão entre pessoas de origens diferentes que enfrentam dificuldades semelhantes.

A alimentação é uma condição necessária da vida animal. Em se tratado de seres humanos, contudo, essa necessidade não se limita aos critérios nutritivos. Cada ato relacionado ao "comer", tal como caçar, plantar, preparar ou servir o alimento, está imbuído de um imaginário e uma constelação de significados e práticas compartilhados. As diferentes culturas elegem não somente aquilo que se come, mas também o como, o quando, o porquê e com quem se come (Maciel, 2001).

Apresento como a necessidade de se alimentar e de enviar comida aos familiares na Venezuela constitui a principal motivação de venezuelanos/as para permanência no Brasil, mesmo trabalhando em condições adversas, sem acesso a direitos sociais e tratados/as como pessoas inferiores. Busco analisar as diferentes agências envolvidas nos atos de receber, enviar e compartilhar comida. As relações descritas, embora estejam ligadas com a atividade laboral, não se restringem a esse campo, mas também afetam e são afetadas pelo estreitamento de laços de amizades, fortalecimento do vínculo familiar à distância e a interação com os/as brasileiros/as.

Na perspectiva de problematizar a comida como elemento propulsor do deslocamento de venezuelanos/as para Boa Vista, me aproprio da discussão promovida por Carlos Fausto (2013) na esteira de Marylin Strathern (2012) sobre "feeding and eating", traçando analogias entre as ações de dar/receber comida e comer junto, tal qual agenciadas pelos/as venezuelanos/as. O objetivo 
de Fausto era explorar a diferença entre "dar comida" e "comer junto" para os indígenas da Amazônia, questionando: "O que os atos produzem? Quais as agências e perspectivas envolvidas? Que tipo de relação configuram?" (Fausto, 2013, p. 156). Em outras palavras: quem alimenta quem? Quem come com quem? Instigada por essas inquietações e canibalizando ${ }^{1}$ o pensamento desses autores sobre o tema, procuro refletir sobre as relações entre pessoas venezuelanas e brasileiras em Boa Vista. A comparação dos distintos processos aponta semelhanças, tais como o estabelecimento de relações assimétricas (predação) e a inexistência de uma alienação plena da agência do outro, mesmo em posição de dependência.

Venezuelanos/as vivenciam três momentos no Brasil: receber comida dos brasileiros, enviar comida aos parentes na Venezuela e a possibilidade de comer como iguais (com outros venezuelanos). O primeiro é marcado pela relação de trabalho assimétrica com os brasileiros/as, cuja centralidade está na exploração de sua mão de obra e na necessidade vital de conseguir comida. Já no segundo, consiste na transição entre a condição de sujeito passivo (que recebe comida) para a de agente (que dá comida), concretizada pelo envio de remessas aos seus familiares na Venezuela e o status de provedor. O terceiro é assinalado pela comensalidade estabelecida entre pessoas venezuelanas que motivadas pelo contexto de deslocamento passam a compartilhar um mesmo ponto de vista e a se perceber como semelhantes (a despeito das diferenças de classe no país de origem), tendo como principal ponto comum a condição de fugitivo da chamada "Dieta de Maduro" - expressão utilizada por venezuelanos/as como analogia ao desabastecimento de gêneros alimentícios atribuído ao governo do presidente Nicolás Maduro².

O artigo está estruturado da seguinte maneira: no primeiro momento, apresento um breve panorama da recente acentuação do deslocamento de pessoas de nacionalidade venezuelana para Boa Vista, capital do estado de Roraima, por meio de notas etnográficas oriundas de pesquisa de campo realizada nos meses de outubro e novembro de 2016 e junho de $2017^{3}$. No segundo momento, descrevo situações sobre venezuelanos/as na cidade de Boa Vista permeadas pelo processo de receber comida, dar comida e comer

\footnotetext{
1 Strathern (2012) argumenta que os antropólogos canibalizam o trabalho de seus pares uma vez que estamos constantemente "comendo" o pensamento uns dos outros.

2 Não é objetivo deste artigo discutir sobre a complexidade da crise venezuelana e suas múltiplas causas, sejam elas internas e/ou externas.

3 Nota metodológica: foram abordados inicialmente indivíduos dos sexos feminino e masculino, com idades entre 20 e 50 anos, nos sinais da av. Venezuela e também na fila para solicitação de refúgio na Polícia Federal em Boa Vista-RR. Os interlocutores apresentados aqui, por meio de nomes fictícios, são aqueles que concordaram em colaborar com o projeto de pesquisa "Mira, Mira: diferencialidades e parentesco de venezuelanos/as e brasileiros/as em Boa Vista e Santa Elena de Uairén", financiado pela FAPESP processo 2016/14055-0.
} 
junto. Nas considerações finais, retomo a discussão sobre as ações de receber, dar e compartilhar comida, apontando as diferenças de agenciamento dos/as venezuelanos/as nas distintas condições de pets, provedores e comensais.

\section{La dieta de Maduro e suas consequências: deslocamento de venezuelanas/os para Boa Vista - RR}

Distante apenas $230 \mathrm{~km}$ da divisa com a Venezuela, Boa Vista tem como principal acesso a BR 174. O trajeto da fronteira até a capital atravessa pequenas localidades e algumas comunidades indígenas, sem qualquer controle do fluxo migratório, realizado somente no posto da Polícia Federal no município fronteiriço de Pacaraima. A principal via de tráfego para quem chega da Venezuela em Boa Vista após percorrer a BR174 é a Av. Venezuela. Esta é uma das vias mais movimentadas da capital roraimense. Ela é continuidade da BR que, em sentido sul, conecta Roraima ao estado do Amazonas e, para o norte, se encerra na fronteira com o país Venezuela. A avenida é marcada por estabelecimentos comerciais, especialmente ligados ao setor de autopeças e serviços de mecânica, que dividem espaço com agropecuárias, escola, postos de gasolinas, restaurantes, farmácias, prédios públicos e vários sinais de trânsito no cruzamento com outras grandes avenidas igualmente movimentadas que interligam bairros de urbanização mais recente com a parte central e mais antiga da cidade. Coincidência ou não, era local onde se concentraram, num primeiro momento, a maioria dos/as venezuelanos/as que chegavam a Boa Vista e onde pude estabelecer os primeiros contatos.

É meio-dia. O sol está a pino. O termômetro do carro marca 44 ํㅡ célsius. Saindo da Universidade Federal de Roraima, horário de almoço, carros parados no sinal de trânsito na Av. Venezuela. Por causa do calor, a maioria dos carros está com as janelas fechadas, ar condicionado ligado. Pouca gente ousaria estar sob o sol numa hora dessas na linha do equador. Um rapaz falando português misturado com espanhol aparece na frente do para-brisa, espirra água com sabão no vidro e depois uma moça retira o líquido espumante com o rodo. Tudo é muito rápido. A duração do sinal é curta. Mal tenho tempo de verificar se tenho algumas moedas na bolsa. Encontro 50 centavos e, pela janela, entrego ao rapaz que começou o "serviço", enquanto o sinal verde provoca o movimento abrupto dos carros.

Seguindo pela avenida, dou azar e fico parada em outro sinal. Desta vez, surge à esquerda do carro uma senhora com os cabelos lisos muito negros, pele queimada de sol, roupas coloridas, pescoço cheio de colares de miçanga. Sem falar nada, ela ergue uma latinha vazia e sugere pedir dinheiro. Agora, para azar dela, o meu último trocado fora compartilhado no sinal anterior. Com a negativa da doação, a senhora ofereceu os colares em troca, talvez, de qualquer quantia em dinheiro. Ela não fala português e tampouco demonstrou 
reconhecer o meu portunhol. Balbuciou alguma coisa em seu idioma, cuja origem não consegui identificar naquele momento (descobri depois que se trata do povo Warao). O sinal abriu e eu segui o caminho.

O movimento na avenida é constante, sobretudo nas primeiras horas da manhã, no intervalo do almoço e ao pôr do sol. Os carros fazem pequenas filas nos semáforos fechados. Mesmo sob sol escaldante, homens e mulheres com sotaque espanhol avançam sobre os veículos munidos de garrafas de água com sabão, rodos e flanelas e disputam a limpeza de para-brisas em troca de um pagamento e/ou doação incerta. Enquanto isso, outros oferecem produtos eletroeletrônicos, gêneros alimentícios, fazem malabarismos e mulheres indígenas pedem dinheiro e oferecem artesanato e mel. A comunicação com os/as motoristas é comumente realizada pelo portunhol. Já no caso dos/as indígenas a distância linguística torna ainda mais difícil a negociação entre esse grupo e os/as motoristas brasileiros/as.

A presença de comércio ambulante e pedintes nas esquinas de Boa Vista é algo recente. Tal fato vem causando estranheza aos moradores da pequena capital de 332 mil habitantes (IBGE, 2017) desacostumados, seja no centro da cidade, nos bairros nobres ou populares, com a presença de moradores de ruas e pessoas oferecendo coisas nos sinais de trânsito. Apenas com a chegada de milhares de venezuelanos, a cena muito comum em grandes centros urbanos do Brasil tornou-se também parte do cotidiano boa-vistense.

Durante minha estadia em Boa Vista, cena parecida ocorreu, cotidianamente, sempre na mesma avenida. Breves diálogos ocasionais, travados em portunhol, revelaram as diversas origens dos inusitados lavadores/ as de vidros, pedintes e vendedores ambulantes. "Yo vengo de Maturín"; outro veio desde "cerca de la frontera con Colombia"; "Llegué de Maracaibo hace veinte días"; há gente do litoral, das montanhas, de diferentes regiões da Venezuela, incluindo a capital Caracas. Isso sem contar com as mulheres, homens e crianças do povo Warao. São pessoas com origens diversas. A Venezuela está representada do Oriente ao Ocidente e da Amazônia ao Caribe.

$\mathrm{Na}$ realidade da fronteira Brasil-Venezuela, Boa Vista, enquanto capital do estado de Roraima, é o centro de convergência dos aparatos estatais e institucionais, políticos e econômicos da região, produzindo aos olhos de quem se desloca da Venezuela a possibilidade de maiores oportunidades de emprego (Vasconcelos, 2013).

A chegada de milhares de venezuelanos/as em Boa Vista vem modificando o cenário local. Ao percorrer a cidade é possível identificar várias fachadas de estabelecimentos comerciais com nomes e termos em espanhol. O idioma espanhol disputa lugar com o português. A grande maioria dos/ as venezuelanos/as que chegaram à cidade está se inserindo no setor de 
prestação de serviços dada as peculiaridades da economia local, marcada pelo funcionalismo público e um setor industrial incipiente.

A escolha da capital roraimense como cidade de destino deve-se tanto à localização estratégica da fronteira terrestre que torna o deslocamento mais acessível, quanto ao reconhecimento pelos/as venezuelanos/as da sua condição temporária na cidade em busca de trabalho e renda. O objetivo é levar comida para as famílias na Venezuela; uma forma de combater o que eles/as chamam de "la dieta de Maduro". A expressão diz respeito a uma atribuição de responsabilidade ao atual governante sobre o desabastecimento de gêneros alimentícios. Não cabe aqui discutir se existe mesmo essa responsabilidade unilateral do governo Maduro, se a culpa é do mercado petrolífero ou da pressão dos opositores nacionais e internacionais. O que chama atenção é a centralidade do tema "alimentação" quando se referem à situação que lhes constrange a tentar a sorte no Brasil e em outros países.

Para estender o tempo no Brasil, sem sofrer perseguições policiais e ameaças de deportação, meus/minhas interlocutores/as venezuelanos/as contam que lançaram mão do pedido de refúgio. Uma vez iniciado o processo, é possível acessar, ainda que temporariamente, direitos sociais no Brasil, como carteira de trabalho e escola para as crianças. Além disso, o tempo de tramitação do processo jurídico-político-burocrático permite mais tempo ganhando dinheiro e comprando comida no Brasil.

Estamos esperando ver o que sucede por aqui. Tratando de conseguir sair por aqui, pois é mais fácil para voltar e ver família na Venezuela. Vamos ver o que sucede até a metade do ano que vem que encerra o prazo do refúgio. Como já te comentei eu não quero ficar no Brasil, mas tenho refúgio por causa da documentação para não termos problemas na rua, uma estratégia para permanecer aqui e poder trabalhar. Então, você imagina! Tudo que nós deixamos para entrar e de supetão te lançam para Santa Elena e você retorna com a mão vazia. Eu com quatro crianças! Por isso precisamos buscar uma maneira de permanecer aqui. Tudo é uma sobrevivência aqui. (Mulher, 35 anos, natural de Maturín, entrevista em 25/11/2015)

A narrativa da mulher descortina a centralidade do acesso aos documentos para consolidação da condição de cidadã em terras estrangeiras. Por outro lado, tratando-se do acionamento do refúgio no caso das famílias transnacionais venezuelanas também têm perspectiva inversa. As entradas e saídas para visitar os parentes na Venezuela precisam ser realizadas por caminhos não mapeados. As forças policiais brasileiras (federal e estadual) estão empenhadas em controlar as fronteiras e dificultar essa mobilidade.

Todas as vezes que vou para Venezuela ou volto de lá venho com o "credo en la boca", pois tenho a solicitação de refúgio que me dá direito a permanecer 
até julho do ano que vem no Brasil, mas quando volto da Venezuela não posso registrar entrada no Brasil para não perder esse direito. Vivo essa condição de ilegal. A última vez que voltei da Venezuela vim sozinha. No táxi lotação que eu peguei em Pacaraima veio com puro brasileiros. A única venezuelana era eu. Quando o carro parou no posto da Polícia Federal o policial perguntou: Tem algum venezuelano aí? Graças a Deus, como já tinha contado a minha situação para o taxista e para os outros brasileiros que vinham no carro, todos me apoiaram e responderam que não. Assim, vamos seguindo, toda vez que saímos vamos sem a certeza de poder voltar. (Mulher, 35 anos, natural de Maturín, entrevista em 25/11/2015)

O documento no contexto de deslocamento venezuelano "legaliza e oficializa como cidadãos e os tornam visíveis, passíveis de controle, e legítimos para o Estado" (Peirano, 2006, p. 137). A solicitação de refúgio faz dos/as venezuelanos/as "cidadãos em termos performativos e compulsórios" (ibidem). Contudo, a obrigatoriedade legal também pune quem não atende as exigências. Realizando uma comparação com a etnografia desenvolvida por Crovetto (2015) entre os documentos dos tripulantes mercantes chilenos da cidade portuária de Corral, ousaria a dizer que no caso das solicitações de refúgio dos/as venezuelanos/as em Boa Vista, "seu conteúdo é transnacional, sua emissão é nacional e sua leitura é local" (ibidem, p. 32).

Isso também reverbera nas ações estatais em relação às políticas migratórias em Roraima. O caso dos/as venezuelanos/as na avenida Venezuela é um exemplo bastante ilustrativo. Com base nas interações entre os níveis transnacional, nacional e local é possível sugerir que em âmbito municipal a prefeitura preza por ações de "higienização" e expulsão dos venezuelanos. Em âmbito estadual, existem inciativas precárias de políticas de acolhimento, como abrigos improvisados em ginásios esportivos ${ }^{4}$ e policiamento ostensivo de inibição do trabalho de pessoas venezuelanas nas grandes avenidas da cidade. Já a Polícia Federal se mantem sempre presente em espaços de discussões sobre ações de acolhimento e integração dos/as venezuelanas em Boa Vista, mas tendo em vista o caráter complexo de suas atribuições, também protagoniza ações de deportação em massa ${ }^{5}$. Por conseguinte, concordo com Peirano (2006, p. 137) que aponta que essa obrigatoriedade legal impede o reconhecimento social do indivíduo que não tenha documentos.

Nesse ambiente complexo crescem os grupos provenientes de diferentes localidades na medida em que redes de parentesco são estabelecidas em

\footnotetext{
4 No âmbito da estrutura de governo foi criado em 2016 o Gabinete Integrado de Gestão Migratória gerido pela Defesa Civil, o qual presta apoio aos chamados Centros de Referência ao Imigrante (abrigos improvisados), dirigidos pela organização ecumênica "Fraternidade Federação Humanitária Internacional".

5 Somente no dia 09/12/2016, 450 venezuelanos/as, em sua maioria indígenas, foram conduzidos coercitivamente até a fronteira (cf. <http://folhabv.com.br/noticia/Policia-Federal-faz-operacaopara-deportar-450-venezuelanos-ilegais-/23253>, acesso em: 18.01.2018).
} 
Pacaraima e, em maior número, em Boa Vista. Na esteira de Ingold (2011, p. 234) sugiro que o conhecimento adquirido pelos venezuelanos no ambiente de Boa Vista não é transmitido, mas fruto de sua ação cotidiana que implica no englobamento permanente da percepção e ação "dentro do campo das relações estabelecidas por meio da imersão do ator-observador em determinado contexto". Aprender a viver e comer como brasileiro/a é requisito fundamental para o acesso a algum tipo de trabalho e/ou alguma atividade que gere renda e garanta recursos mínimos para o envio de comida para família na Venezuela. Assim, após delinear esse breve panorama, problematizaremos na sessão seguinte a comida como mecanismo propulsor da mobilidade e como elemento importante na construção das pessoas desses indivíduos deslocados.

\section{Pets, presas, provedores e comensais}

Já era fim de tarde, o sol começava a se recolher quando caminhei até o primeiro sinal da avenida Venezuela, cerca de dois quarteirões. Eram por volta das 17:30, por sorte o dia não estava tão quente quanto o de costume e muitos carros transitavam com as janelas abertas. Ao me aproximar do sinal, fui abordada por um homem que entregava panfletos, falando em portunhol. O nome dele era Rodolfo José, estatura mediana, corpo robusto e pele vermelha do sol, aparentando em torno de cinquenta anos, corria de um lado ao outro em busca de entregar centenas de panfletos promocionais de um supermercado local na eminência de atingir a meta imposta pelo patrão. Rodolfo contava altivo que antes o chefe precisava enviar três pessoas para entregar panfletos naquele horário, agora sozinho conseguia fazer todo o serviço. A conquista da carteira de trabalho e do emprego formal há pouco mais de um mês, ainda em fase de teste, no supermercado após aquisição do protocolo de pedido de refúgio era também motivo de orgulho, pois agora tinha dinheiro para se alimentar e alimentar a família. Com olhos umedecidos me contou que quando chegou em Boa Vista precisou vender todas as ferramentas de pedreiro para comprar comida.

Rodolfo veio de Puerto Ordaz e há cerca de seis meses vivia em Boa Vista e agora tinha como principal empreendimento a manutenção do emprego no supermercado e para isso fazia todo tipo de serviço. "Todo lo hago: limpiar el piso, llevo cajas y por la tarde los folletos, no recuso nada!". Rodolfo contou que saiu da Venezuela porque lá era impossível viver e trabalhar. Com pouca formação, tem o ofício de pedreiro, mas desde que chegou a Roraima, "faz de tudo". Tem quatro filhos, embora esteja separado da mãe de seus filhos, todos os meses envia dinheiro para comprar comida para os filhos na Venezuela.

Os/as venezuelanos/as estão dispostos/as a trabalhar em qualquer atividade subalterna, a despeito de suas qualificações. Existem médicos vendendo pitombas nas esquinas da capital, arquitetos lavando pratos em 
restaurantes e advogados empacotando caixas em supermercados. Ainda que suas profissões sejam necessárias em Roraima, não é possível exercê-las no Brasil sem antes enfrentar um longo processo burocrático-acadêmico-político. A "inconsistência de status" à qual os/as venezuelanos/as se submetem revela o impacto da conjuntura econômica em seu país. A "inconsistência de status" seria a desvalorização das potencialidades profissionais do migrante que, mesmo sendo tecnicamente capacitado, não está socialmente reconhecido (Sayad, 2001; Cavalcanti, 2014). A opção por trabalhar no Brasil, mesmo em condição desfavorável, é explicada com pragmatismo: aqui é possível comprar comida para toda a semana com o pagamento de um dia de trabalho informal.

Boa Vista, por oferecer (a ilusão de) maiores oportunidades de emprego, vem atraindo famílias para residência temporária. Os/as venezuelanos/as procuram trabalhar e estão se inserindo como podem nos mercados de trabalho boa-vistenses. Oferecem lavagem de para-brisas nos semáforos, fazem comércio ambulante de mercadorias chinesas, trabalham em restaurantes, ou ainda são empregados informalmente no comércio e na construção civil, com salários abaixo dos/as trabalhadores/as brasileiros/as, além de serem recrutados/as para trabalharem em fazendas e nos municípios do interior como pedreiros e/ou ajudantes. Os trabalhos nos municípios do interior do estado de Roraima são ainda mais precários, relegados a um lugar desconhecido e sem terem como voltar. É comum a descrição de experiência de condições análogas à escravidão, nas quais o valor combinado a ser pago é descontado quase pela metade no ato do pagamento em troca da comida fornecida pelo contratante.

Em algumas relações com os brasileiros a condição de pessoa do/a venezuelano/a é diminuída, sendo tratado enquanto o "outro de fora". Isto posto, realizo uma analogia com a diferença que Carlos Fausto (2013) faz entre dar/receber comida e comer junto. Para os Kanamari, do Acre, oferecer comida (para criança, para xerimbabo, para um subordinado) significa uma relação assimétrica, de posse. Os exemplos etnográficos dos povos amazônicos descritos por Fausto são ilustrativos para refletirmos sobre a subordinação imposta pelos brasileiros aos venezuelanos/as em Boa Vista.

No caso dos animais de estimação dos Kanamari, quando aprisionados por seus donos perdem autonomia de comer sozinhos, pois têm dentes, asas e unhas extraídos do seu corpo, o que debilita sua capacidade física de conquistar seu próprio alimento. Um paralelo pode ser desenhado, tendo em vista a condição dos venezuelanos. No caso, a debilidade do corpo não foi causada diretamente pelos brasileiros, senão pela conjuntura política e econômica do estado venezuelano, anedoticamente chamada de "Dieta do Maduro" pelos solicitantes de refúgio. Ao atravessar a fronteira com o Brasil, os/ as venezuelanas/os arriscam-se em terras desconhecidas, tornando-se mansos e vulneráveis às condições impostas pelos/as brasileiros/as. Como "de fora" ou 
"cidadão de segunda classe", como se percebem, assumem a condição de sub gente no território onde a gente do lugar é que têm direitos. Uma vez no Brasil, sua posição é de passividade na relação dar/receber comida. Existe uma perene instabilidade em sua capacidade de receber comida ou pagamento justo por parte dos brasileiros.

Desta condição passiva de recebedor de comida, os venezuelanos transitam para uma posição de provedor quando abordamos o tema das remessas para os familiares que ficaram na Venezuela. Assumem, no ato de enviar comida, uma posição ativa na qual se permitem enxergar novamente enquanto pessoas plenas e capazes de garantir o próprio sustento e dos entes queridos. Meu interlocutor Rodolfo ressalta que o vínculo de pai é reforçado com o dinheiro enviado à família para comprar comida. Assim, alimentar a família significa contê-la dentro de si enquanto provedor (ibidem).

$\mathrm{Na}$ busca eminente pela comida tornam-se mansos a todas as formas de negação de direitos. Aceitam entrar em relações de trabalho precária e preferem estar no Brasil mesmo que não sejam reconhecidos socialmente como cidadãos/gente, no caso dos indocumentados, aos olhos do Estado (Peirano, 2006; Crovetto, 2015). No pendulo entre as condições de ser e não ser pessoa no sentido do acesso aos direitos sociais brasileiros, os/as venezuelanos/as oferecem sua força de trabalho a qualquer preço para garantir a própria sobrevivência e a de seus familiares que ficaram na Venezuela.

Em busca de receber e dar comida, os/as venezuelanos/as experimentam duas possibilidades que provocam as reflexões deste artigo: ser transformado em pet (animais de estimação) ou virar presa. Me apropriando dos exemplos etnográficos de Fausto (2013) como alegoria para refletir sobre a realidade venezuelana em Roraima, diria que os venezuelanos se transformam em pets por meio de uma relação de trabalho estreitada por laços de amizade gerados nos pequenos favores como doação de roupa usada, indicação para pequenos trabalhos na rede local de amizade dos patrões brasileiros e a própria possibilidade de comer junto.

Quando imersos nesse tipo de relação com os/as novos/as patrões/oas podem passar até a comer junto com e/ou como eles, mas assim como os pets nas comunidades indígenas, jamais são considerados plenamente iguais e/ou alguém de dentro.

Cheguei ao Brasil a convite de uma senhora brasileira que me conheceu em Porto Ordaz. Na época trabalhava como segurança numa clínica de estética lá. Contei que era pedreiro. Ela me deu $\mathrm{R} \$ 150,00$ para eu chegar até Rorainópolis para construir um apartamento para ela. Passei um mês lá, considerava uma amiga, pois comíamos juntos à mesa, mas depois que completou um mês e encerrei o trabalho ela descontou mais da metade 
do que eu havia cobrado na comida. Fiquei muito triste! (Homem, 50 anos, natural de San Félix, entrevista em outubro de 2016)

Na Amazônia, assim como no mundo do trabalho capitalista, ou você come junto (mesmo que na condição assimétrica de pet) ou é devorado enquanto presa. Fausto (2013, p. 160) nos conta um caso do inimigo que tentou fugir do cativeiro Tupinambá. Enquanto cativo, o inimigo foi alimentado pelo dono, mas por não ter aceitado a posição de dependência que poderia ser convertida em relação de parentesco, não assumiu o papel de manso, seguiu bravo, tentou fugir, foi caçado e assassinado. No caso dos/as venezuelanos/as a posição de manso é uma condição de integração sociocultural, aceitando a desvalorização da mão de obra e evitando entrar em rota de conflito com os brasileiros. Ao "caminar derecho", como dizem os/as trabalhadores/as venezuelanos/as, eles e elas conquistam reconhecimento por sua condição de trabalhador e cidadão ordeiro, e se distinguem daqueles/as paisanos/as menos controláveis.

A circunstância de se tornar bravos e, consequentemente, presas (da polícia e outras instituições de controle), pode estar associada à não aceitação das condições precárias de trabalho oferecidas, ao não reconhecimento enquanto sujeito de direitos e à resistência frente à imposição de outras formas de se comportar e viver em Boa Vista. Certa vez participando de uma reunião institucional na Universidade Federal de Roraima-UFRR, promovida pela presença dos representantes do Alto Comissariado da ONU para os refugiados (ACNUR), a religiosa responsável pelo Centro de migrações e direitos humanos $(\mathrm{CMDH})$, irmã Telma, relatou na ocasião que precisou atender um venezuelano que havia sido agredido e preso na delegacia da cidade simplesmente por ter denunciado uma situação precária de trabalho. Ou seja, foi capturado como presa por sua postura de indignação.

Seguindo na leitura sobre as relações entre quem dá e quem recebe a comida, podemos pensar sobre pessoas que no seu país jamais se imaginaram comendo juntas, mas que, devido às dificuldades no Brasil, passam a vivenciar tal situação. Em novembro de 2016, enquanto conversava com o senhor Rodolfo na Av. Venezuela, um carro preto parou na esquina do semáforo e dele desceu uma senhora franzina, de cabelos grisalhos, com bastante dificuldade de caminhar. Junto a ela uma outra mulher, mais jovem, apresentando mais energia e vigor. Subitamente juntaram-se em torno das duas, inclusive Rodolfo, todos/as venezuelanos/as que se encontravam nas proximidades. Com feições ligeiramente de alegria acenavam entre si e caminhavam para um lado e para outro como forma de chamar atenção sobre a chegada das mulheres. Em poucos minutos, haviam em torno delas pelo menos três dezenas. As mulheres abriram o porta-malas do carro e começaram a distribuir marmitas. Rapidamente a calçada à direita da avenida se transformou num refeitório ao ar livre. Era possível ver homens, mulheres, adolescentes e crianças sentados 
lado a lado saciando a fome de um dia inteiro de trabalho. Alguns sentados sobre a calçada improvisavam mesas com tijolos justapostos. Outros comiam sobre caixas de papelão. Entre uma "cucharada" e outra, trocavam sorrisos e diálogos em espanhol.

Esse episódio da rua descortina duas situações que acontecem ao mesmo tempo. Por um lado, a relação de dependência para com os provedores/as brasileiros/as, e, por outro, uma relação de comensalidade entre pessoas que compartilham um mesmo ponto de vista (Vilaça, 2005). No caso em questão, costureiras comem junto com designer de ambientes, engenheiros com pedreiros, psicólogas com cozinheiras, tendo como histórico comum o recente enfrentamento da chamada "Dieta do Maduro" que provoca o deslocamento até o Brasil em busca de alimentos, remédios e outros recursos. De acordo com Aparecida Vilaça (ibidem), só é possível comer junto com semelhantes, com aqueles que compartilham uma mesma perspectiva. Confundir simpatia momentânea com amizade e não ser capaz de identificar as assimetrias nas relações de poder ocasiona situações embaraçosas, como no caso de Rodolfo e a fazendeira que demonstrou, ao final, o distanciamento que havia entre empregado e empregadora.

A comensalidade ou com quem comemos, "implica em divisões por sexo, família, idade, status, etc. O com quem envolve partilha, comensalidade, o que transforma o ato alimentar em um acontecimento social" (Maciel, 2001, p. 150). No caso dos venezuelanos, a condição de vulnerabilidade socioeconômica nivela a todos pela carência de meios para a subsistência, ensejando a ideia de que "compartilham um mesmo ponto de vista". Pode-se mesmo dizer que se trata de uma comensalidade situacional. Os marcadores sociais de classe são relativizados em função do contexto de precariedade e essa precariedade comum desperta, entre os diferentes, uma sensação de companheirismo. De acordo com Eunice Maciel:

A palavra companheiro (como no francês compagnon e no inglês companion) provém de cum panem, "os que compartilham o pão". Assim, a comensalidade, o "comer juntos", é o momento de reforçar a coesão do grupo, pois ao partilhar a comida partilham sensações, tornando-se uma experiência sensorial compartilhada. (Maciel, 2001, p. 150)

Para Marshal Sahlins, o ato de comer junto remonta a uma noção clássica de família (do latim famulus - aqueles que se alimentam junto em torno de um mesmo fogo). Pessoas que compartilham intimamente da existência uns dos outros, partilham uma "mutualidade do ser" e são "membros uns dos outros" (Sahlins, 2013). No contexto do deslocamento de venezuelanas/os para Boa Vista, podemos sugerir, compartilhando pensamento de Machado (2013, p. 155), que a mobilidade, em si, tanto fabrica quanto é produto do parentesco. 
Parentes estão relacionados por meio de substâncias como sangue, sêmen e comida. Quem chegou primeiro assume uma condição de "gerente". Partindo do exemplo do senhor Rodolfo, no processo de reunificação familiar em Boa Vista, filhos e noras que antes tinham autonomia financeira em relação a ele na Venezuela, passam a ser dependentes dele no Brasil. Sem conhecer a cidade e sem possuir relações de amizade e afinidades consolidadas, os recémchegados têm suas vidas e a possibilidade de receber e dar comida mediados por Rodolfo. Neste contexto, relações hierárquicas são criadas e fortalecidas assim como afinidades e afetividades estremecidas ganham novo combustível: "Falo para esse rapaz, você precisa aprender a viver como brasileiro, tem que aprender a falar a língua e aceitar qualquer trabalho. Antes vivíamos apartados, agora estamos unidos, pouco a pouco um vai ajudando o outro".

Certa vez enquanto estava conversando com Rodolfo durante o final de semana, período no qual presta serviços temporários como capinar quintais para ganhar um dinheiro extra, testemunhei a seguinte situação: a patroa foi pagá-lo e dividiu o valor correspondente ao serviço prestado em partes iguais entre ele e o filho adotivo Hector que realizara a atividade em conjunto. Rodolfo prontamente interrompeu a ação e disse: "La senhora pode entregar o dinheiro para mim, eu sou o gerente". Hector deu apenas um sorriso e não questionou nada. Um mês depois chegaram a esposa de Hector e outro filho de Rodolfo com sua esposa. O grupo passou a viver sob a liderança de Rodolfo, para quem a conquista de um trabalho dependeria da aquisição de um ethos de "brasilidade" como falar português (pelo menos portunhol), comer farinha, ser amável e aceitar qualquer tipo de atividade sob quaisquer circunstâncias.

Realizando uma comparação com a etnografia de Machado (2014) entre os trabalhadores brasileiros na cidade do Porto em Portugal, podemos deduzir que a "venezuelidade" em Boa Vista opera ao contrário da "brasilidade" no Porto. Enquanto os brasileiros no Porto são sujeitos ativos no processo de exotização e afirmação de suas características diferenciadoras (ibidem, p. 32) os/as venezuelanos/as em Boa Vista tentam chamar pouca atenção para suas diferenças e, de certo modo, adquirir uma certa "brasilidade" como estratégia de inserção no mercado de trabalho. Note-se que a "brasilidade" dos venezuelanos em Roraima não é a mesma "brasilidade" dos brasileiros em Portugal. No Porto, os trabalhadores/as brasileiros/as estudados/as por Machado cultivam sua imagem de alegria, simpatia e cordialidade em contextos específicos do mercado de trabalho que o autor classificou como "mercado da alegria" (ibidem, p. 32). Os/as brasileiros/as utilizam essa "brasilidade" a seu favor numa certa "hierarquia de alteridades" presentes em Portugal (ibidem, p. 32-33). Já os/as venezuelanos/as em Boa Vista, procuram se mostrar cordiais, mas precisam retrair a alegria e se oferecer como trabalhadores ordeiros e homens/mulheres "de família". O adjetivo homens e mulheres de família é 
empregado justamente como negação de uma vida festeira e denota um certo amansamento em relação à moralidade cristã dos brasileiros. Quiçá, conquistar a condição de semelhante e comensal.

A comensalidade aqui não é apenas uma transição que se dá com o tempo, mas uma transformação nos parâmetros estruturais (Fausto, 2013, p. 158). Ou seja, no caso dos/as venezuelanos/as não é a fixação no lugar, mas o fato de aprender a língua, como se comportar e onde conseguir emprego. $\mathrm{Na}$ qualidade de manso (pet), Rodolfo critica quem se apresenta como arredio. Para ele, viver em terras estrangeiras implica em aceitar a condição de desigual e, no seu modo de ver, somente alianças e novas relações de afinidade podem trazer uma transformação em igual. Ele próprio já experimentou a condição de "presa" quando foi demitido do supermercado porque "hablava mucho". Por isso, atualmente, Rodolfo se esforça na construção de uma persona abrasileirada tendo em vista conseguir um casamento com mulher nacional deste país e se tornar "um de dentro", superando a condição de forasteiro.

Na maioria dos casos, por cobrarem uma remuneração menor em relação a outros trabalhadores/as nos postos de trabalho da mesma função, tendem a ser considerados potenciais inimigos. Na predação da exploração capitalista em relação à oferta da mão de obra, os/as venezuelanos/as são canibalizados pelos patrões e transformados em inimigos pelos/as trabalhadores/as nacionais que ocupam a mesma classe social. "Tá difícil de trabalhar aqui em Boa Vista com a chegada desses venezuelanos. Trabalham em troca até de comida" ${ }^{6}$.

Os/as venezuelanos/as se esforçam para repelir o estigma de "problema" diante da opinião pública boa-vistense, reivindicando para si uma ética trabalhadora. A maioria condena a mendicância e procura demonstrar, inclusive nas esquinas, a existência de uma relação de trabalho, no caso, uma prestação de serviço. Fazem questão, como no caso de Rodolfo, de frisar sua diferenciação perante aqueles venezuelanos que descumprem a legislação e os costumes brasileiros. Valorizam a postura de manso e condenam uma postura arredia que acaba caindo na marginalidade e virando presa dos poderes policiais.

Sugiro, compartilhando o pensamento de Vilaça (2005, p. 448) que assim como na Amazônia a condição de humanidade dos/as venezuelanos/as em Boa Vista também é uma posição que precisa ser continuamente definida. Não ter casa, não ter família, não ter emprego, não saber falar a língua, não possuir documentos, e não se comportar de forma ordeira, produz no/a venezuelano/a uma impressão de ser menos humano.

6 Homem, 45 anos, entrevista em 31/03/2017. 


\section{Considerações finais}

Entre idas e vindas e nas relações com os/as brasileiros/as, as pessoas venezuelanas vivenciam no cotidiano da capital roraimense diferentes experiências. Os atos de receber, enviar e compartilhar comida são importantes aspectos a serem considerados. Produzem nestes indivíduos diferentes tipos de agenciamento e perspectivas que podem configurar relações assimétricas e simétricas. Para cada situação, destacamos, respectivamente, um tipo de agência: pet, provedor e comensal.

A subordinação imposta pelos/as brasileiros/as aos venezuelanos/as em Boa Vista em busca de comida impõe, para sua grande maioria, uma condição de pet ou presa. A condição de pet emerge da aceitação da condição de desigual, de fora, ao mesmo tempo, que também se configura como estratégia de integração sociocultural e acesso ao mercado de trabalho. Assim como os animais de estimação dos indígenas amazônicos, a posição de pet dos/as venezuelanos/as denota uma certa afinidade com seus patrões e patroas, observável em pequenos gestos na convivência cotidiana. A oferta de comida, convites para comer à mesa, doações de roupas e indicações para outros trabalhos são interpretados pelos venezuelanos como marcadores de uma relação de proximidade.

A agência aqui é eclipsada por uma relativa passividade emergente da aceitação de formas precárias de trabalho que produz certa instabilidade na capacidade de receber e dar comida. Por outro lado, essa mesma circunstância abjeta possibilita que assumam a posição de agentes uma vez que os capacita enquanto doadores/as-provedores/as de comida aos seus familiares que ficaram na Venezuela.

A condição de presa dos/as venezuelanos/as em relação aos brasileiros/as é estabelecida quando demonstram algum tipo de indignação e resistência na relação com os brasileiros. O desconhecimento dos trâmites institucionais e legais no Brasil, a falta de domínio do idioma português e a situação de outsider os deslocam da condição de pet para a condição de presas.

Por outro lado, a mesma mobilidade que reduz a noção de pessoa e tolhe o exercício da cidadania em terras estrangeiras também proporciona o estabelecimento de relações simétricas por meio de uma nova comensalidade. Venezuelanos e venezuelanas que dificilmente se perceberiam como iguais no seu país, seja pelas diferenças de níveis de formação e classe social, agora não só comem juntos, quanto compartilham o mesmo ponto de vista no que diz respeito aos reflexos da crise econômica e política em sua terra natal. A "dieta de Maduro" e os desafios enfrentados pelo deslocamento até Boa Vista para a materialização da existência individual e de suas famílias traduzem-se num 
cenário de dependência que é uma condição compartilhada, a despeito das diferenças de status na Venezuela.

Com base na comparação dos diferentes contextos vivenciados pelos/as indígenas na Amazônia e pelos/as venezuelanos e venezuelanas em Boa Vista é possível concluir que os atos de receber, enviar e compartilhar comida podem corresponder a processos divergentes que envolvem distintas capacidades de agência, nas quais a ação de se alimentar pode significar afirmação de uma condição de semelhança ou uma questão de poder e posse, configurando-se, respectivamente, em relações simétricas (comer junto) e assimétricas (receber e enviar comida).

\section{Referências bibliográficas}

BEHERAN, Mariana; FREITAS, Patricia T. Trajetórias migratórias e inserção laboral de jovens migrantes bolivianos (as) em oficinas de costura nas cidades de São Paulo e Buenos Aires. In PEREIRA, Gloria S.; PEREIRA, José R. (orgs.). Migração e Globalização - um olhar interdisciplinar. Curitiba: Editora CRV, 2011, p. 265-292.

CAVALCANTI, Leonardo. Imigração e mercado de trabalho no Brasil: características e tendências. In: CAVALCANTI, Leonardo; OLIVEIRA, Antonio Tadeu; TONHATI, Tânia (orgs.). A inserção dos Imigrantes no Mercado de Trabalho Brasileiro. Brasília: Cadernos do Observatório das Migrações Internacionais, 2014.

CROVETTO, Gonzalo Díaz. Entre lugares y documentos: problematizando el desplazamiento y las condiciones transnacionales del viaje y del trabajo de tripulantes corraleños. Antipoda - Revista de Antropologia y Arqueologia, n. 23, p. 23-44, 2015.

FAUSTO, Carlos. Feeding (and Eating): Reflections on Strathern's 'Eating (and Feeding). Cambridge Anthropology, v. 31, n. 1, p. 156-162, Spring 2013.

FELDMAN-BIANCO, Bela. Deslocamentos, Desigualdades e Violência do Estado. Ciência e Cultura, v. 67, p. 20-24, 2015.

IBGE, Instituto Brasileiro de Geografia e Estatística. Estimativas da população residente para os municípios e para as unidades da federação brasileiros com data de referência em $1^{\circ}$ de julho de 2017. Rio de Janeiro: IBGE, 2017. Disponível em: <https://cidades.ibge.gov.br/brasil/rr/boa-vista/panorama>. Consultado em: 07.2018

INGOLD, Tim. Being alive: essays on movement, knowledge and description. New York: Routledge, 2011.

MACHADO, Igor José Renó. Movimento e parentesco: sobre as especificidades dos deslocamentos. Campos - Revista de Antropologia Social, v. 15, n. 1, p. 27-42, 2014.

MACHADO, Igor José Renó. Parentesco e diferencialidades: alternativas à identidade e às fronteiras étnicas no estudo das migrações. In: FELDMAN- BIANCO, Bela (org.). Os desafios da Antropologia Brasileira. Brasília: ABA, 2013, p. 153-173. 
MACIEL, Maria Eunice. Cultura e alimentação ou o que têm a ver os macaquinhos de koshima com brillat-savarin?. Horizontes Antropológicos, v. 7, n. 16, p. 145156, 2001.

PEIRANO, Mariza. A teoria vivida e outros ensaios de antropologia. Río de Janeiro: Editora Jorge Zahar, 2006.

SAHLINS, Marshall. What kinship is - and is not. Chicago: University of Chicago Press, 2013.

SAYAD, Abdelmalek. A imigração ou os paradoxos da alteridade. São Paulo: EDUSP, 2001.

SILVA, João Carlos Jarochinski; BÓGUS, Lucia Maria Machado; Silva, Stéfanie Angélica Gimenez Jarochinski. Os fluxos migratórios mistos e os entraves à proteção aos refugiados. R. Bras. Est. Pop., v. 34, n. 1, p. 15-30, 2017.

SIMÕES, Gustavo da Frota (org.). Perfil sociodemográfico e laboral da imigração venezuelana no Brasil. Curitiba: CRV, 2017.

STRATHERN, Marilyn. Eating (and Feeding). Cambridge Anthropology, v. 30, n. 2, p. 1-14, 2012.

VASCONCELOS, lana dos Santos. Articulações familiares transnacionais: Estratégias de cuidado e manutenção familiar na fronteira Brasil/Venezuela (Dissertação de mestrado). UFPE/UFRR, 2013.

VILAÇA, Aparecida. Chronically unstable bodies: reflections on amazonian corporalities. Journal of the Royal Anthropological Institute, v. 11, n. 3, p. 445464, 2005.

Recebido para publicação em 26.01.2018

Aceito para publicação em 27.02.2018

Received for publication in January 26 ${ }^{\text {th }}, 2018$

Accepted for publication in February $27^{\text {th }}, 2018$

ISSN impresso 1980-8585

ISSN eletrônico 2237-9843

http://dx.doi.org/10.1590/1980-85852503880005309 